\title{
AN INFORMATIVE CONTENT 3D MODEL FOR THE HALL HOLDING THE RESURRECTION OF CHRIST BY PIERO DELLA FRANCESCA MURAL PAINTING AT SANSEPOLCRO, ITALY
}

\author{
M. Coli ${ }^{1}$, A. L. Ciuffreda ${ }^{1}$, M. Micheloni ${ }^{1},{ }^{*}$ \\ ${ }^{1}$ Department of Earth Sciences, University of Florence, Via G. La Pira 4, 50121 Firenze, Italy - coli@ unifi.it, \\ annalivia.ciuffreda@virgilio.it, michelangelo.micheloni@unifi.it
}

KEY WORDS: HBIM, Piero della Francesca, Sansepolcro, 3D model, cultural heritage, mural painting

\begin{abstract}
:
The Resurrection of Christ by Piero della Francesca (about 1460) at Sansepolcro (Italy) is a masterpiece in the development of painting. The painting is located in a hall of the city government building, which today holds the Civic Museum of Sansepolcro. This mural painting was realized on a brick wall $(15 \mathrm{~cm}$ thick) located in a different place as it is today. Shortly later, the painting was moved by means of a transport to solid-wall and placed against a pre-existing wall $(60 \mathrm{~cm}$ thick), where it is today, erecting against this wall a counter wall $(15 \mathrm{~cm}$ thick) where the mural painting wall-panel $(225 \times 200 \mathrm{~cm})$ had been inserted.

Within the studies aimed at restoration and conservation of the painting, the type and characteristics of the walls of the museum hall and of the wall where the painting is located have been defined through different types of diagnostic surveys. Geometric, physical, mechanical and material data from surveys are knowledge that must be archived and made accessible for future maintenance operations. Building Information Modeling (BIM) is a valid methodology that allows to build a three-dimensional database in which to collect information about diagnostics and conservation of the historical building. The aim of this paper is digitalization through the HBIM methodology of the hall of Resurrection, in order to create a "3D informative model" that describes the geometry with objects linking them the information related to knowledge of cultural heritage and it can represent a technical and organizational support for future conservation operations.
\end{abstract}

\section{INTRODUCTION}

This work is part of the international research field that investigates the potential of BIM (Building Information Modelling) applied to cultural heritage. The BIM methodology is currently used in architecture and engineering because it allows to insert the properties and information of a project into a three-dimensional model. Moreover, using parametric models and their attributes, BIM allows extract two-dimensional drawings from the 3D model and managing a large amount of data related to the entire building. These aspects make this methodology the best way to manage projects on cultural heritage, from the survey phase to restoration work.

The management of an existing building through an "informative model" presents the well-known difficulties related to the elaboration of the survey, to the modeling of very complex and non-standard forms and to the modalities of data entry in a univocal and easily consultable way. Nevertheless, this work aims to test the possibility of an approach based on HBIM.

Starting from a modelling based on traditional survey methods, on historical data (drawings, archival documents and bibliography available) and on the results of extensive survey campaigns, we want to demonstrate how this tool proved to be suitable for reconstructing the complex shapes of the architectural asset and at the same time has constituted a repository of all the data for a correct georeferencing of the information supporting the conservation and restoration activities carried out on the painting.

The case study examined is represented by the hall holding the Resurrection of Christ by Piero della Francesca (Figure 1), inside the Civic Museum of Sansepolcro (Italy). In the last years, the Sansepolcro Municipality supported a series of studies regarding the structural behaviour of the hall where the Resurrection of Christ is located, in order to safeguard it from seismic hazard. These studies are also preparatory to the intervention of restoration of mural painting occurred in 20162018 by the Opificio delle Pietre Dure.

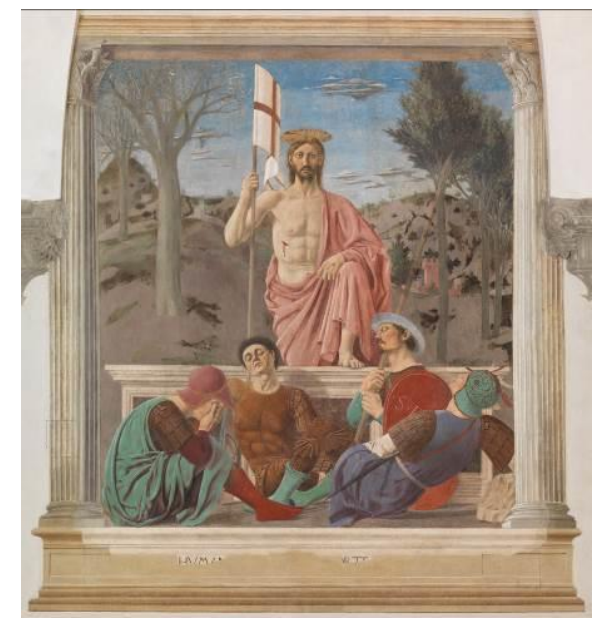

Figure 1. The mural painting the Resurrection of Christ by Piero della Francesca at Sansepolcro (Italy), about 1460.

To achieve the objectives of the research the Department of Earth Sciences has carried out the surveys, in line with the guidelines of the MIBACT 2011 Guidelines (point 4.1.6) and in full cooperation with the Museum, Opificio delle Pietre Dure and local Superintendent. The surveys conducted concerned the

\footnotetext{
* Corresponding author
} 
type and characteristics of the walls that make up the museum hall and the wall where the wall painting is placed. The history of the building and its current assembly was studied and was performed a series of non-destructive tests (NDT): GPR, sonic and ultrasonic, microendoscopy and thermal. The dynamic behaviour of the room has been defined through an FEM analysis and has been correlated with the results of the 5-year work monitoring system.

\section{BIM APPLIED TO HISTORIC BUILDINGS: STATE OF ART AND NORMATIVE REFERENCES}

The preservation of the historical and artistic heritage in Italy is an important issue given the richness and fragility of this territory. For this reason, its protection cannot be separated from an in-depth diagnostic knowledge that is preparatory for every type of intervention on heritage.

The MIBACT 2010 Guidelines $^{1}$, dedicated to historicalmonumental buildings, draw attention to the historical and constructive knowledge of the building, providing indications on how to acquire this knowledge.

The organization and management of knowledge acquired on a building is always quite complex. Often the phases of a restoration project overlap and there is a lack of coordination between the different disciplines participating. Information is exchanged hastily, through different media support and over time tend to be lost, forgotten and difficult to use by future users.

The introduction and use of digital models in restoration allows not only to investigate the geometry of the building, but also to store in a single "container" (2D or 3D), the information related to the preliminary phase, of project, site and maintenance.

In this sense, the $\mathrm{Sicar}^{2}$ (Information System for restoration sites), is an example of GIS application created to manage documents and analyses collected during the restoration and connect them to a 2D geometric model of the building.

Although there have been significant developments in the research for the attribution of content and information to threedimensional models for the management of historical heritage, the applications of 3D-GIS (Geographical Information Systems) have remained isolated experiences (Baratin et al., 2014).

As an alternative to the construction of a 3D GIS, the international scientific community has started a process to understand the possibilities of application to the historical architecture of the BIM process as a tool for classifying, managing and analysing information.

The first use of BIM applied to existing buildings is represented by the works of Arayici (2008) which attempts a first 3D modelling with integration of intelligent data.

In the same years the experiments of Murphy et al. $(2009 ; 2013)$ to the. develop the Historic Building Information Modeling (HBIM) by creating libraries of parametric objects constructed from historical data and a system for mapping the parametric object onto a cloud of points.

In the interesting work of Volk (2014), the limits and the poor application of BIM on existing buildings are discussed through a critical analysis of numerous contributions in the literature.

\footnotetext{
1 "Linee guida per la valutazione e la riduzione del rischio sismico del patrimonio culturale con riferimento alle Norme tecniche per le costruzioni di cui al decreto del Ministero delle Infrastrutture e dei trasporti del 14 gennaio 2008 "

${ }^{2}$ Developed within the project ARTPAST (Applicazione informatica in Rete per la Tutela e la valorizzazione del Patrimonio culturale nelle aree Sottoutilizzate).
}

Some of the issues expressed in the contributions are still current: difficulties in the modelling of non-standard forms, lack of automation in the conversion of data acquired from digital surveys into semantic objects, methods for entering information and documents. Even today, in the practice of the restoration project, BIM is still not widespread and often used as advanced $\mathrm{CAD}$, neglecting its essence: information and its sharing.

However, contributions about HBIM are multiplied in an attempt to solve problems by simplifying the restoration project workflow or opening new way for experimentation.

Regarding the modelling of objects starting from a point cloud, there are interesting contributions by Garagnani and Manferdini (2013) and Barazzetti et al. (2015a). In literature, there are examples of enrichment of the model through information insertion or reconstruction of the evolutive phases of the building (Apollonio et al., 2013; Brumana, et al., 2013). The experiments of the integration between BIM and GIS in the research of Dore and Murphy (2012) are interesting.

Another aspect of significant importance is the exploration of the methods of consultation by external users (even nonprofessionals), the BIM model through web platforms and augmented reality (Barazzetti et al., 2015b) or the construction of databases for the building maintenance (Fassi et al., 2015).

The BIM legislation in Europe has as reference the "European Union Public Procurement Directive" 2014/24 of 26 February 2014. The standard invites EU Member States, by 2016, to encourage or impose through legislation, the use of BIM for all projects with public funding. Italy has adopted UNI 11337 (divided into 10 parts), opening the discussion on the use of the BIM methodology to cultural heritage. This topic must necessarily be treated, since this tool is spreading and will become the mandatory reference standard for public projects.

\section{THE HALL OF PIERO: HISTORICAL AND CONSTRUCTIVE ANALYSIS}

The following section describes the research and analysis carried out to understand the constructive method and the state of conservation of the Piero della Francesca Resurrection wall support.

In paragraph 3.1 will perform a historical-constructive analysis of the building that hold the painting by Piero della Francesca.

In paragraph 3.2 will analyze the types of cognitive surveys carried out on the wall that supports the painting; while in paragraph 3.3 will be showed the results obtained.

The information deriving from the cognitive framework outlined has been included in the BIM model as described in section 4 .

\subsection{Historical and constructive analysis of the Conservatori Palace}

The building that was originally the Conservatori Palace and holds the painting the Resurrection by Piero della Francesca, today is incorporated in the aggregate building of the Museo Civico di Sansepolcro (Figure 2).

The building currently consists of three levels with a rectangular plan $(44 \times 9 \mathrm{~m})$ and height of about $14 \mathrm{~m}$. A central wall divides the volume in an almost symmetrical way in two parts with dimensions of about $22 \times 9 \mathrm{~m}$

The basement floor overlooks via Fiorenzuola and is buried on opposite sides. The halls of Piero della Francesca and Matteo di Giovanni are located at the ground floor. In the attic floor are visible the extrados of the vaults of the two lower halls and the floor built in 1939 on the vault of the hall of Piero. 
The first floor is made by cross vaults in bricks (two heads). Brick barrel vaults (a head) make the second floor. The rebuilt vaults of Piero della Francesca's room are hung on a floor with tables on metal beams, except for the part near the building's façade.

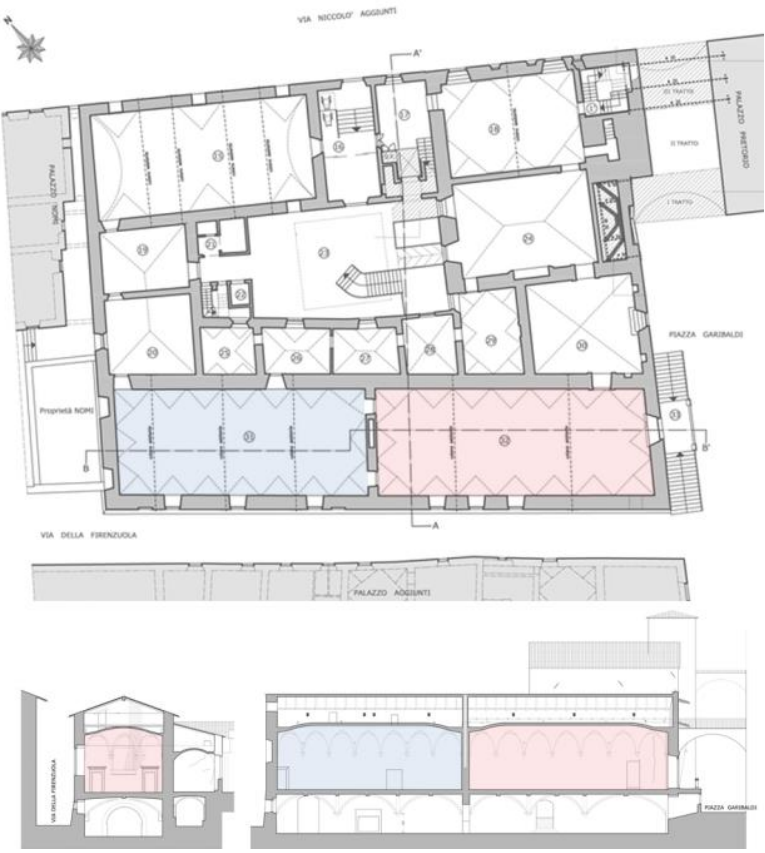

Figure 2. Survey of the Civic Museum of Sansepolcro. In red, the hall of the painting by Piero della Francesca; in blue the hall of Matteo di Giovanni; in the middle the wall that holds the painting. (Survey provided by the Municipality of Sansepolcro).

The current roof was built in 1967. This roof is made with trusses formed by "Varese" joists in prefabricated reinforced concrete and steel chains. In 2017, a consolidation of the structures was carried out by positioning structural reinforcements above the vaults or on the floor of the attic.

The most complete reconstruction of the historical events of the palace is written by C. Blasi (2004), reported here with the additions deriving from A. Cecchi (2012) and A. Borri (2015).

The building was built in the XIV century as a large hall for public assemblies. In the XV century the hall was divided into the two current smaller halls with the construction of wall in false. This wall had a fireplace and a chimney in the hall of Matteo di Giovanni, while in the basement it had been reinforced with an arch. In 1474, the original wooden ceiling was replaced with barrel vaults and lunettes.

A little bit later, on the side opposite the fireplace, the Resurrection of Christ mural painting was placed by means of transport to solid-wall. For this purpose, against the pre-existing wall $(60 \mathrm{~cm}$ thick), was erected a counter wall $(15 \mathrm{~cm}$ thick) where the mural painting wall-panel $(225 \times 200 \mathrm{~cm})$ had been inserted.

In the XVIII century, the Monte dei Pegni (Figure 3) uses the building. Between the XVIII and XIX centuries in the hall of Piero a false wall was built and three doors were closed in the right wall; two doors on the sides of the painting was opened and closed, while the fireplace was closed.

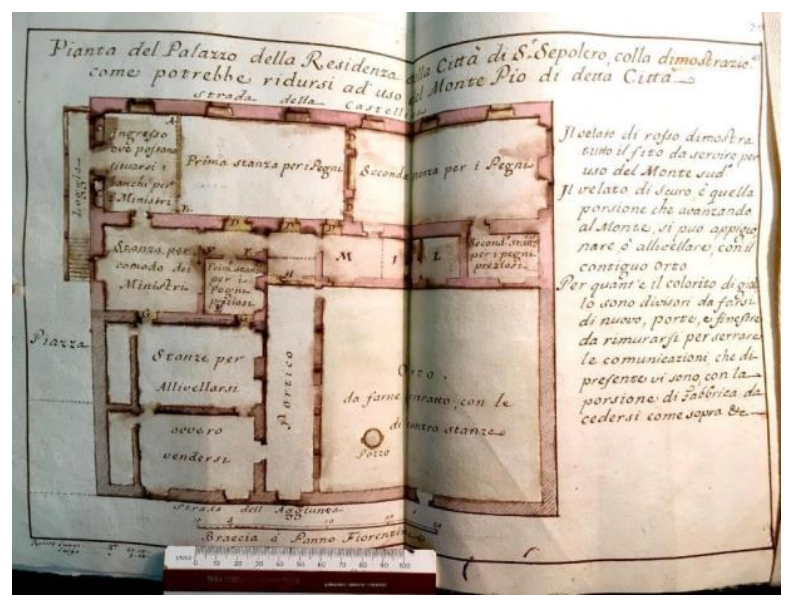

Figure 3. Map of the state of the places and works planned for the settlement of Monte dei Pegni, mid XVIII century (Paola Benigni, in print).

In 1900 various structural interventions were carried out: the consolidation of the vault of the Piero's hall by hooking the NP beams resting on the walls; demolition and reconstruction of the central part of the vault; replacement of the wooden truss roof with Varese trusses with a thrust eliminated by steel tie rods; replacement of the filling of the vaults with lightened clay and insertion of chains after the earthquake in Umbria in 1997.

\subsection{Surveys and analysis for the definition of the cognitive framework}

In order to acquire information on the construction methods and the conservation status of the painting's wall, we carried out the surveys and analysis described below.

The construction of the 3D BIM model was based on the survey provided by the Municipality of Sansepolcro with some checks that we carried out during the inspections.

At the outline of the wall painting there is a large fissure that delimits the painting with finishes and subsequent completions. Along this fissure, without affecting the painting, seven exploratory inspections were opened by removing the plaster. In some inspections, it was possible to carry out direct survey/video inspections in the masonry due to the lack of continuity between the painting and the boundary walls. The chimney of the old fireplace has an opening at the level of the attic that allowed it to be explored from above with direct observation and video-inspection.

The part of the wall underneath the painting was investigated in the hall of Matteo di Giovanni through six DAC-Tests: microperforation $(\varnothing 1 \mathrm{~cm})$, rotary controlled at low pressure and with sampling tip of the resulting powder. The depth of the perforation has never been greater than $30 \mathrm{~cm}$.

For the sonic reliefs was used a percussion hammer at various altitudes from the floor. The data of sonic surveys and DACTest allowed evaluating the compactness of the wall structure.

All around the mural painting there is a fissures pattern monitored in the last fifteen years. The instruments record seasonal movements of the order of $0.01 \mathrm{~mm}$, in the events of 2016 remote earthquakes the movements reached the order of $0.2 \mathrm{~mm}$ in both the events with no drift towards enlargement of the opening.

Considering the fissures pattern of the painting's wall (Blasi, 2004), a Georadar survey was made on the portion of the wall 
of the painting ${ }^{3}$. A sheet of plexiglass (thickness $2 \mathrm{~mm}$ ) was used to protect the painting. For the surveys, a $2 \mathrm{GHz}$ antenna with double arrays was used in order to perform vertical and horizontal measurements. The georadar survey highlighted the internal structure of the investigated wall portion, the discontinuities/empty spaces present and the different types of materials. The chimney and the fireplace are evident both in the empty part and in that filled with incoherent material.

During the surveys also the mortars present were analysed, both as a binder of the bricks, and in plasters or infill ${ }^{4}$. Mineralogical analyses were performed using X-ray diffractometry (XRD). Petrographic analyses were performed by light transmitted optical microscope.

Within these studies, was performed the dynamic identification of the parts of the building of the halls of Piero della Francesca and Matteo di Giovanni and a dynamic analysis of the building. Indeed, the Sansepolcro area presents a strong historical seismicity (six earthquakes > VII MCS in the last 1000 years), which caused several damages to buildings; moreover in the IIWW the Nazi retiring blasted some edifices causing local vertical rebound up to $1 \mathrm{~g}$.

The measurements for the dynamic identification were carried out using as a signal the environmental vibrations due to traffic and instrumental intensity microsisms. The dynamic response of the structure has been identified by means of seismometers (velocimeters) placed in nodal positions of the structure ${ }^{5}$.

The 3D finite element model was built using the SAP2000 software (® Computers and Structures, Inc). To consider the contribution of the adjacent building part, these were also included in the model. The modelling was carried out in the linear elastic field. In the absence of experimental data on the masonry (cores and flat jacks) for the materials were considered literature data, "calibrating" the elastic modules based on the experimental results of the dynamic tests.

\subsection{Results achieved}

The result of the analysis outlines the lateral walls of the halls were built by means of mortared sandstone stone slabs and boulder (thickness $110 \mathrm{~cm}$ ).

The entire wall of the painting has a thickness of about $78 \mathrm{~cm}$ and is composed of different parts assembled at different times. The original wall to which the counter wall of the painting has been placed has built by means of mortared bricks and sandstone boulder (thickness $60 \mathrm{~cm}$ ), with a soft link to the lateral previous walls.

Inside this wall, the fireplace and the chimney were made of bricks of $30 \times 15 \times 5 \mathrm{~cm}$, placed by flat, and with mortar of about $1 \mathrm{~cm}$. In the attic is visible the wall that encases the chimney (Figure 4).

Inside the chimney, a vertical lesion was found between the wall of the cavity and that of the back of the chimney towards the side with the counter wall. It is probably due to seismic causes, or to the blast input due to the Nazi's demolitions.

The portion of the wall on which the painting stands is made up of a brick wall (thickness $15 \mathrm{~cm}$ ), laid out flat, $5 \mathrm{~cm}$ high and with mortar levels of about $1 \mathrm{~cm}$ (Figure 4).

The lower and upper masonry and lateral containment of the painting is made of bricks with a plaster thickness of $2 \div 3 \mathrm{~cm}$.

\footnotetext{
3 The Georadar survey were carried out in collaboration with IDS Georadar S.R.L. (Exagon Group, Pisa).

${ }^{4}$ The mortars were sampled and analyzed by the Materials Analysis Laboratory (LAM) of the Department of Earth Sciences.

5 Measurements made by the Experimental Geophysics Laboratory (LGS) of the Department of Earth Sciences.
}

The counter-wall that supports and contains the wall of the painting is made of bricks, (thickness $15 \mathrm{~cm}$ ) and rises up to the floor of the vaults (Figure 4).
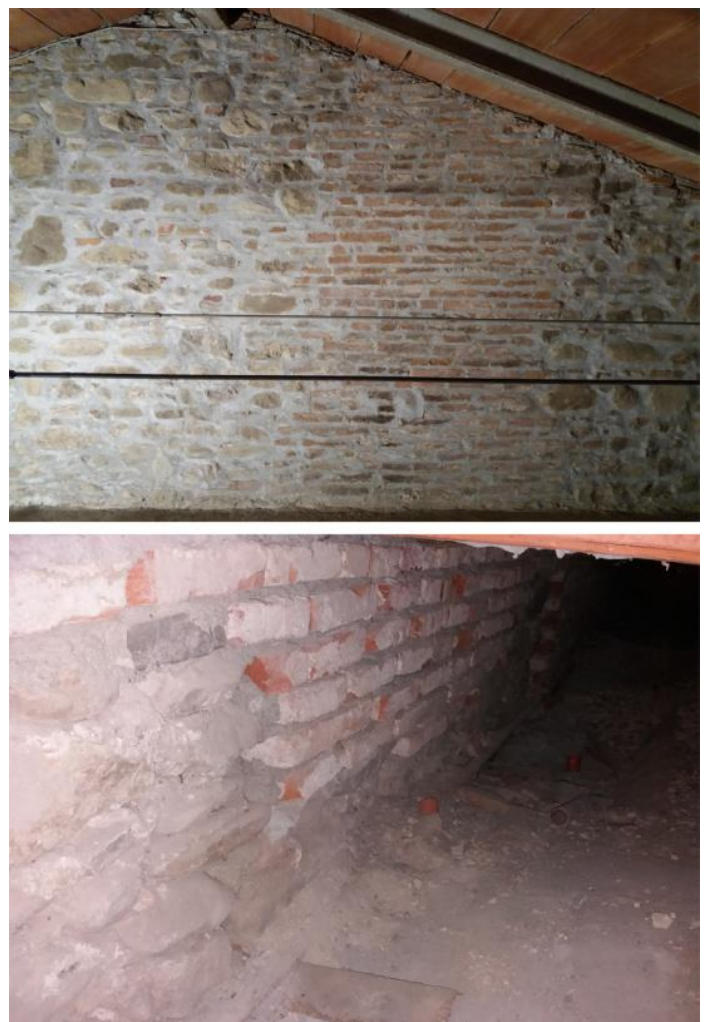

Figure 4. Up: the intermediate wall in the attic where the counter wall supporting the mural painting wall-panel is not present. Down: the counter wall supporting the mural painting wall-panel above the vault but below the attic floor.

The counter-wall to the side of the painting is made by mortared cobbles. The closing of the chimney on the wall of the back room is made of bricks $(8 \mathrm{~cm})$.

The "peduccio" of the vaults were added behind the closing of the fireplace. The installation of the "peduccio" on the right of the painting involved the fireplace requiring an internal support structure. The doors between the two halls seem to have been opened later. The structure of the fireplace appears cut off and replaced to the right of the painting by the doorjamb.

The bricks analyzed have the same type and composition, referable to local materials. The mortars for bedding the solidwall of the painting, of the lateral buffering, the rear wall, and the first level of bricks above the painting, are similar and referable to local materials. The mortars of the two levels of plaster at the top and of the lodging of the bricks above the painting, present a different typology. These aspects would lead to the hypothesis of their attribution to an intervention after the construction of the rest of the masonry. The mortar of the reconstruction at the base of the vault above the painting is different from the others and this confirms the hypothesis of late interventions.

In conclusion, it appears that the wall on which the Resurrection insists was originally a wall with mortar and stones often about $60 \mathrm{~cm}$, inside, towards the hall of Matteo di Giovanni, there was a fireplace with a chimney. Subsequently on the opposite side a brick stole of about $15 \mathrm{~cm}$ thick was built to be a support and contour to the solid-wall removed panel of the Resurrection of Christ. Later the fireplace was closed and 
inside the chimney the support structure of the "peduccio" was inserted to the right of the painting. The vaults have been advanced of about $15 \mathrm{~cm}$ to overcome the thickness of the counter-wall.

The dynamic analysis showed that the developed model represents with good approximation the dynamic behavior of the real structure in the field of small displacements. The numerical model confirms the lesions reported by Blasi (2004) and shows that the structural interventions achieved have broadened the overall strength of the structure.

The wall of the Resurrection appears to be stressed with smaller efforts than the other walls due perhaps to the median position and the loose connection to the external walls. In fact, if on the one hand the partially "released" behavior of the solid-wall of the painting reduces the seismic actions on it, on the other hand this can lead to the reform of the lateral lesions resulting from the different behavior between the two masonry units.

\section{THE INFORMATIVE MODEL}

In order to organize the data collected during the research, a 3D model of the painting wall was realized to highlight the wall structure, as well as the location of the surveys and their results in a unified framework.

\subsection{The workflow of the project}

The first phase of the work is the analysis of the collected data and the organization in order to study the modelling and the methods of inserting information within the 3D model.

The operational phase consisted of modelling the case study and creating customized families for entering the data of the surveys carried out. The creation of specific abacus allowed the interrogation of the model (Figure 5).

The model was subsequently organized through specific views aimed at displaying the different types of information to be highlighted. The BIM model was designed to facilitate the understanding of the wall structure of the painting (Figure 6), to store information found during the diagnostic campaign and during restoration, and to allow easy viewing and consultation.

\subsection{The modellation}

Resurrection wall modelling was performed using Autodesk Revit software (® Autodesk). The starting data come from a direct survey provided by the Municipality of Sansepolcro, therefore the two-dimensional drawing of the plant of the rooms was imported into Revit for modelling in the BIM environment. The difficulties in modelling objects of cultural heritage are various. However, in this case, the choice to operate using BIM software is aimed at testing the potential for managing information related to cultural heritage. Inside the project, the building has been divided into levels: basement level $-4.65 \mathrm{~m}$, first floor level $+0.00 \mathrm{~m}$ and attic level $+7.65 \mathrm{~m}$. Auxiliary levels were inserted to build the vaults, while the level of the foundations was hypothesized. The modelling was mainly carried out on the plan views following the survey scheme and on $3 \mathrm{D}$ views to verify the correctness of the modelling.

Revit system families were used only for modelling objects such as walls, floors and roofs. The walls were created using wallobjects with customized stratigraphies and materials that had textures suitable to ensure the recognisability of the different structures. Even for the floors, it was taken care to insert the correct stratigraphy. The vaults of the basement and of the halls on the first floor have been modelled using adaptive families or masses in place.
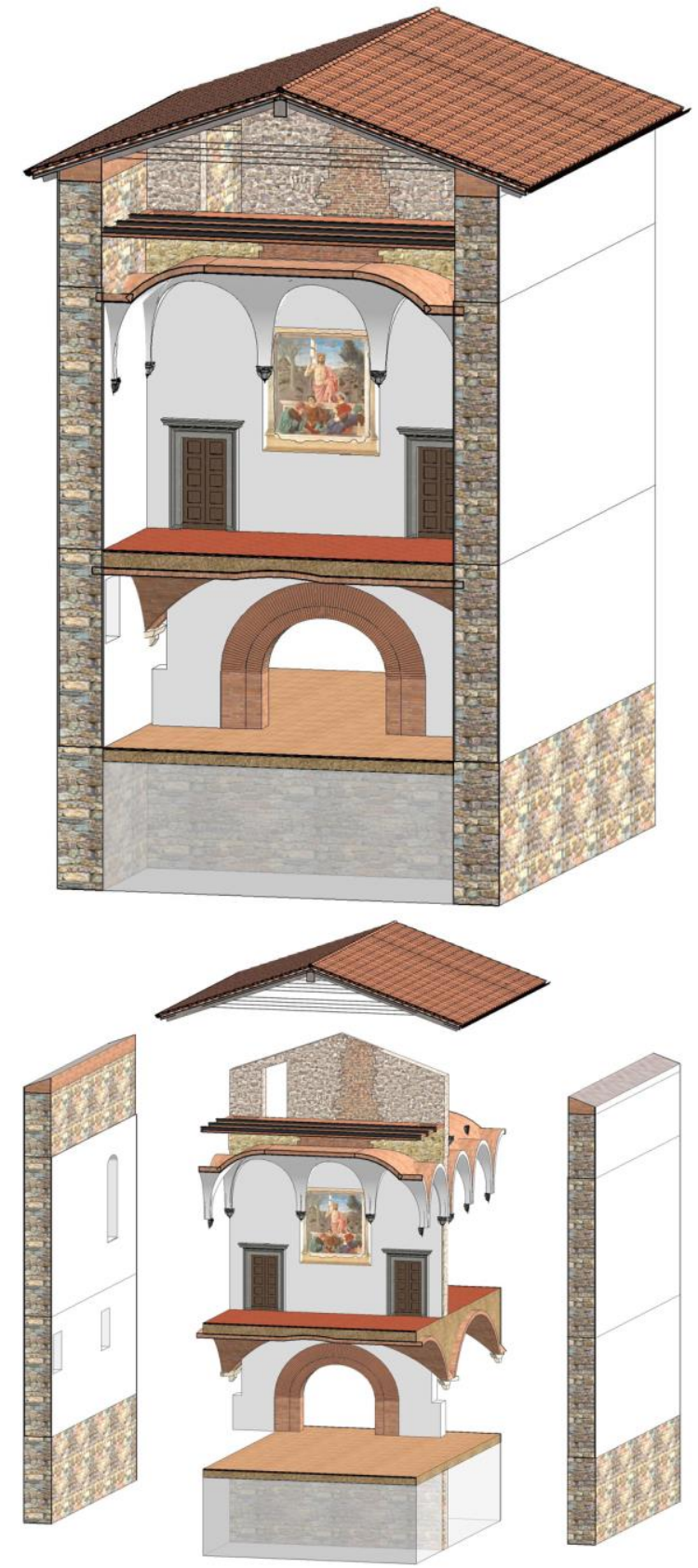

Figure 5. The BIM model. General view.

However, we tried to use as little as possible the modelling in place often discouraged as it results a traditional methodology that comes out from the rules of the BIM creating non-reusable objects that weigh down the file. Therefore, every object that could not be modelled with a system family was inserted starting from a parametrized and personalized family that can be further enriched with information. The roof command was used for the roof, also modelling the beam system that supports it. The doors and windows were modelled in dedicated families.

The insertion of the surveys into the model was addressed through the creation of specific families to which the parameters described in section 4.3 should be linked. The geometry of the objects that represent the surveys has been studied according to the characteristics of the survey itself. For example, a microperforation was modelled as a cylinder with radius and length adjusted by parameters; a georadar survey was modelled on a panel of variable dimensions, etc. This mode allows a 
faster and more efficient visualization and understanding of the model. The same procedure was used for fissures whose geometry follows the real one (Figure 8). In this phase were used the templates of the families of generic and adaptive models.

All this led to create a family library that allowed a rapid modelling of the case study and could be reused in future works.
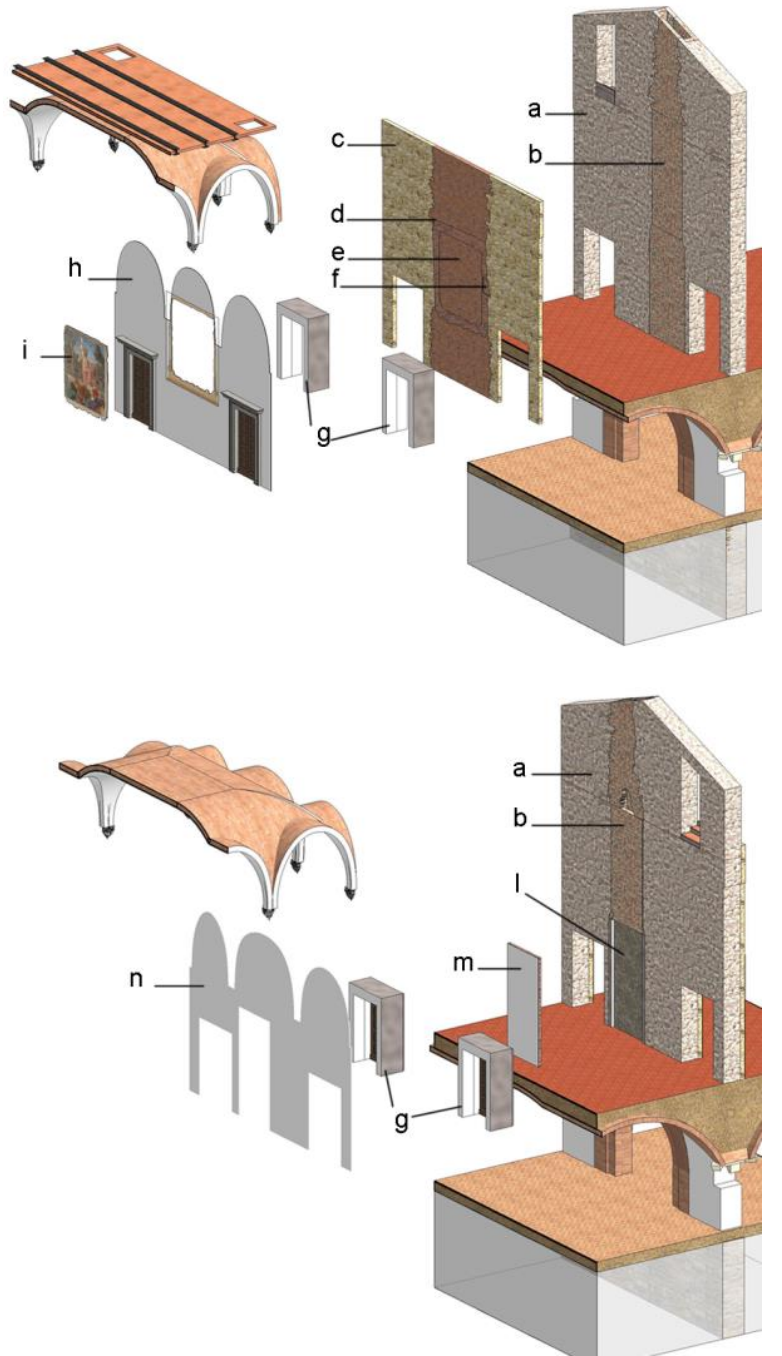

Figure 6. The BIM model. Exploded view: a. the main wall; $b$. the chimney and the fireplace; $c$. the counter-wall of the painting; d. the boundary filling of the solid-wall; e. the solidwall of the painting; $f$. the support block of the "peduccio"; $g$. the reinforcement of the two side doors; $h$. the plaster; i. the painting; 1 . the incoherent filling of the fireplace; $\mathrm{m}$. the closure at the back of the fireplace; $n$. the plaster.

\subsection{The implementation of the informative model}

This work phase illustrates how the data were entered into the model and how it was assigned to each object. The file has been structured that allows to query and display the data entered.

For each element modelled in $3 \mathrm{D}$, it is possible to connect data relating to the general characteristics of the element, to the dimensions, to the results of the analyses, to the materials and to the monitoring data, etc. It is also possible to associate links to external files such as images, videos, documents, etc ...

Each object was created within an appropriate category and preferably associated with instance parameters. All parameters are shared and subsequently converted into project parameters linking them to the relevant category.

The families of the surveys have been associated with parameters that allow to insert information such as the date of execution, the description, the instrument used and the results. It was possible to create parameters to insert links to photos, documents and videos (Figure 7).

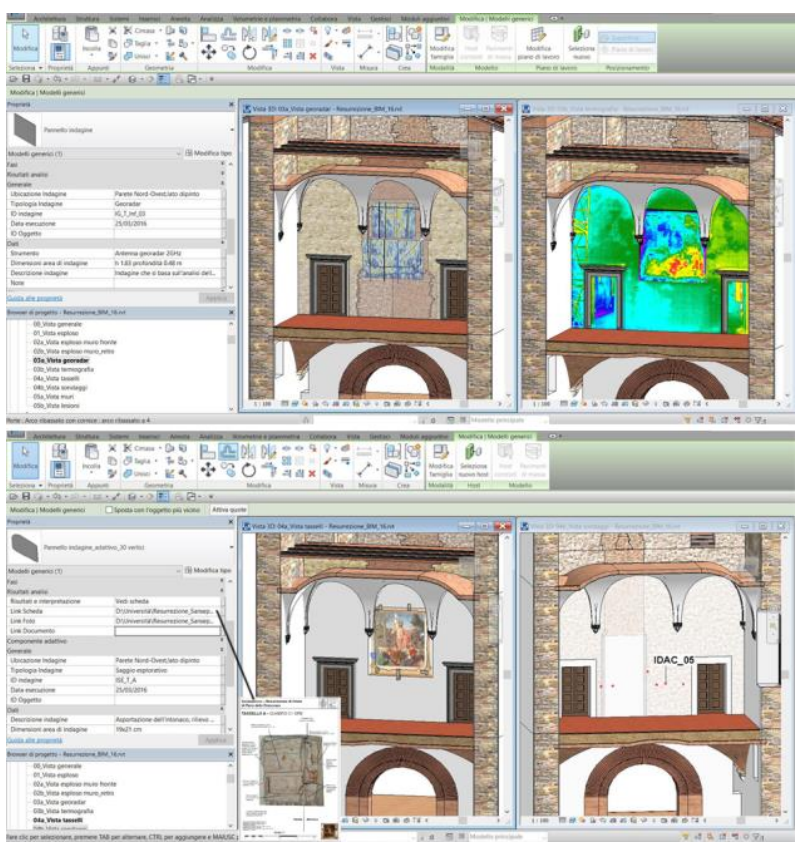

Figure 7. Up: the visualization of georadar and thermography surveys. Down: the visualization of one of the 7 exploratory tests with linked data sheet and of the DAC-tests on the back of the wall with ID label.

For objects such as walls and floor, the inserted parameters describe the structural and technological characteristics of the element: presence of plaster or painted decorations or stucco, mechanical characteristics (modulus of elasticity, specific weight, characteristic resistance, etc.), link to cards that describe report data concerning seismic checks.

Among the parameters of the fissures, it was possible to include information on the characteristics and types of instability and the presence of a monitoring with a link to the eventual measurement card.

Each object has been provided with an ID that identifies it and which can be viewed using the appropriate label. The creation of abacus allowed the classification of the objects by category and the interrogation of the model.

By selecting an element inside the abacus, Revit allows you to view it within the model. Furthermore, the objects inside the schedules can be filtered and sorted according to the parameters created, making it easy to interrogate even very complex models (Figure 8).

Revit software also allows you to manage the visualization of the model through customized views and in the $3 \mathrm{D}$ environment through dynamic sections and exploded view that facilitate in the modelling phase and in the public presentation phase of the research results.

\section{CONCLUSIONS AND FUTURE DEVELOPMENT}

In this study were tested the possibilities of digitization and archiving using BIM methodology applied to a case study of cultural heritage. The model describes with a good level of 
detail the current state of the painting and the structure of its wall support. Furthermore, the information was archived in a simple and easily accessible way.

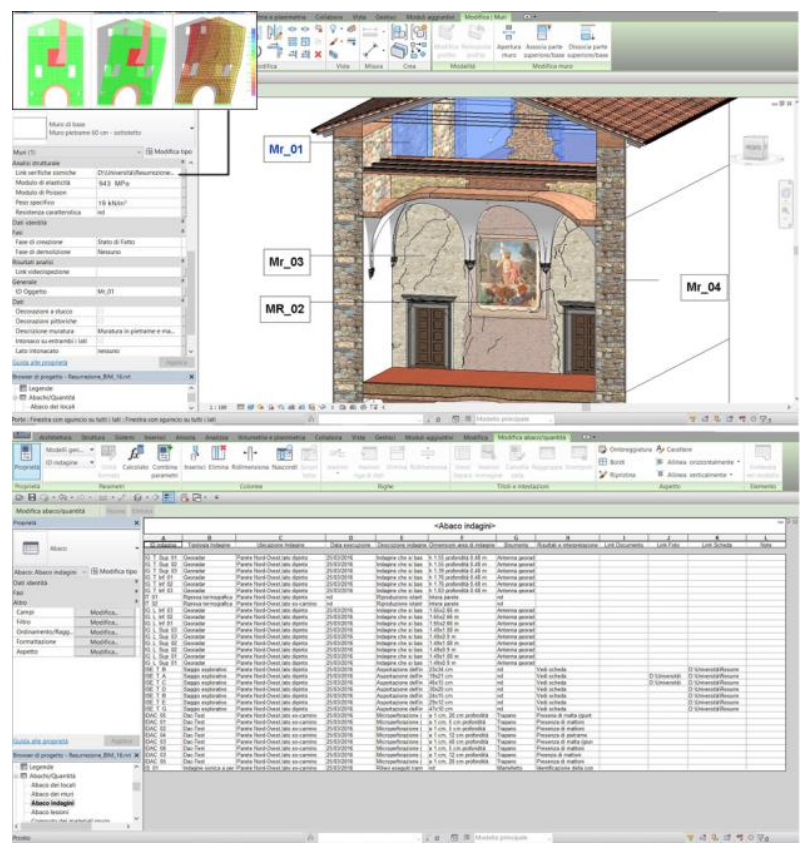

Figure 8. Up: the identification of the walls by label, the visualization of the parameters connected to the object-wall with the link to the dynamic analysis card. The modeling of the fessures pattern is also visible. Down: an example of abacus that allow to manage all the surveys.

All this confirms that BIM is a valid instrument for the management and conservation of historical heritage. Among the advantages of this method is the speed in modeling thanks to the possibility to parameterize elements and to modify them through the variation of the parameters.

A BIM model allows data enrichment and database updating at any time. The model can also be exchanged and viewed through software and online platforms, even by those who have never used BIM software. This opens the way for the dissemination of HBIM with the creation of centralized models with multidisciplinary information that can be used in the field of conservation, but also for the valorization of cultural heritage. Among the problems encountered: the difficulty of modeling elements based directly on the point cloud, the lack of categories related to the restoration process, the absence of information classification procedures and the lack of a unique system that allows the consultation and implementation of the database without the use of BIM software.

Certainly, there are many problems to solve in order to make the BIM process applied to cultural heritage easier. However, this work shows that it is already possible to have an implementable information model. For the future, contributions in this area are already tracing a path towards the creation of complex databases aimed at the management and planned conservation of the existing building heritage.

\section{ACKNOWLEDGEMENTS}

The research was conducted thanks to the contribution of the Municipality of Sansepolcro.

\section{REFERENCES}

Apollonio, F. I., Gaiani, M. and Sun, Z., 2013. 3D modeling and data enrichment in digital reconstruction of architectural heritage, ISPRS-International Archives of the Photogrammetry, Remote Sensing and Spatial Information Sciences, XL-5/W2, pp. 43-48. DOI:10.5194/isprsarchives-XL-5-W2-43-2013.

Arayici, Y. 2008. Towards building information modelling for existing structures, Structural Survey, 26, pp. 210-222. DOI: $10.1108 / 02630800810887108$.

Barazzetti, L., Banfi, F., Brumana R. and Previtali M., 2015a. Creation of parametric BIM object from point clouds using NURBS. The photogrammetric Record, 30 (152), pp. 339-362. DOI: $10.1111 /$ phor. 12122 .

Barazzetti, L., Banfi, F., Brumana, R., Oreni, D., Previtali, M. and Roncoroni, F. 2015b. HBIM and augmented information: Towards a wider user community of image and range-based reconstructions. ISPRS-International Archives of the Photogrammetry, Remote Sensing and Spatial Information Sciences, XL-5/W7, pp. 35-42. DOI:10.5194/isprsarchives-XL5-W7-35-2015.

Blasi, C., 2004. Convenzione tra MIBAC, Soprintendenza BAPSAE di Arezzo e Dipartimento di Ingegneria Civile, dell'Ambiente, del Territorio ed Architettura dell'Università di Parma.

Borri, A., 2015. Convenzione per finalità di studio e ricerca tra Soprintendenza B.A.P.S.A.E. di Arezzo e Università degli Studi di Perugia e Dipartimento di Ingegneria, relazione conclusiva.

Brumana, R., Oreni, D., Raimondi, A., Georgopoulos, A., Bregianni, A., 2013. From survey to HBIM for documentation, dissemination and management of built heritage. The case study of St. Maria in Scaria d'Intelvi. Proceedings of the DigitalHeritage 2013-Federating the 19th Int'l VSMM, 10th Eurographics GCH, and 2nd UNESCO Memory of the World Conferences, Plus Special Sessions from CAA, Arqueologica 2.0 et Al. IEEE, pp. 497-504. DOI:10.1109/DigitalHeritage.2013.6743789.

Cecchi, A., 2012. Lavori di miglioramento sismico del Museo Civico di Sansepolcro, Relazione, Comune di Sansepolcro.

Dore, C., Murphy, M., 2012. Integration of Historic Building Information Modeling (HBIM) and 3D GIS for recording and managing cultural heritage sites. 2012 18th International Conference on Virtual Systems and Multimedia. IEEE, pp. 369-376. DOI:10.1109/VSMM.2012.6365947.

Fassi, F., Achille, C., Mandelli, A., Rechichi, F., Parri, S., 2015. A new idea of BIM system for visualization, web sharing and using huge complex 3D models for facility management. ISPRS -International Archives of the Photogrammetry, Remote Sensing and Spatial Information Sciences, XL-5/W4, pp.359366. DOI:10.5194/isprsarchives-XL-5-W4-359-2015.

Garagnani, S., Manferdini, A.M., 2013. Parametric accuracy: building information modeling process applied to the cultural heritage preservation. ISPRS - In International Archives of the Photogrammetry, Remote Sensing and Spatial Information Sciences XL-5/W1, pp. 87-92. DOI:10.5194/isprsarchives-XL5-W1-87-2013. 
Murphy, M., McGovern, E., Pavia, S., 2013. Historic Building Information Modelling - Adding intelligence to laser and image based surveys of European classical architecture. ISPRS Journal of Photogrammetry and Remote Sensing 76, 89-102. DOI:10.1016/j.isprsjprs.2012.11.006.

Murphy, M.; McGovern, E., Pavia, S., 2009. Historic building information modelling (HBIM). Structural Survey 27, 311-327. DOI:10.1108/02630800910985108.

Volk, R., Stengel, J., Schultmann, F. 2014. Building Information Models (BIM) for existing buildings - literature review and future needs, Automation in Construction 38, pp.109-127. DOI: 10.1016/j.autcon.2013.10.023. 